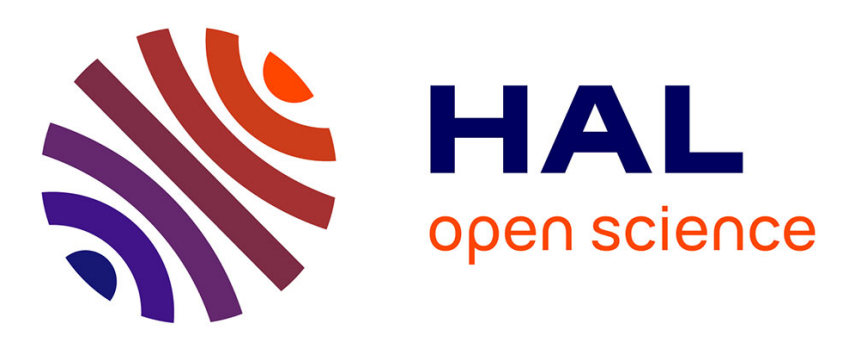

\title{
Development of poly(3-hydroxybutyrate-co-3-hydroxyvalerate)/boron nitride bionanocomposites with enhanced barrier properties
}

Mualla Öner, Gülşah Keskin, Gülnur Kizil, Celine Pochat-Bohatier, Mikhael Bechelany

\section{To cite this version:}

Mualla Öner, Gülşah Keskin, Gülnur Kizil, Celine Pochat-Bohatier, Mikhael Bechelany. Development of poly(3-hydroxybutyrate-co-3-hydroxyvalerate)/boron nitride bionanocomposites with enhanced barrier properties. Polymer Composites, 2019, 40 (1), pp.78-90. 10.1002/pc.24603 . hal01675224v2

\section{HAL Id: hal-01675224 \\ https://hal.umontpellier.fr/hal-01675224v2}

Submitted on 10 Jun 2021

HAL is a multi-disciplinary open access archive for the deposit and dissemination of scientific research documents, whether they are published or not. The documents may come from teaching and research institutions in France or abroad, or from public or private research centers.
L'archive ouverte pluridisciplinaire HAL, est destinée au dépôt et à la diffusion de documents scientifiques de niveau recherche, publiés ou non, émanant des établissements d'enseignement et de recherche français ou étrangers, des laboratoires publics ou privés. 


\title{
Development of poly (3-hydroxybutyrate-co-3-hydroxyvalerate)/boron nitride bionanocomposites with enhanced barrier properties
}

\author{
Mualla Öner ${ }^{*}$, Gülşah Keskin ${ }^{a}$, Gülnur Kızıl ${ }^{a}$, Celiné Pochat-Bohatier ${ }^{b}$, Mikhael Bechelany ${ }^{b}$ \\ ${ }^{a}$ Yildiz Technical University Chemical-Metallurgical Faculty, Chemical Engineering Department, \\ Istanbul, Turkey \\ ${ }^{b}$ Institut Européen des Membranes, UMR 5635, Université de Montpellier, ENSCM, CNRS, \\ Place Eugéne Bataillon, F-34095 Montpellier cedex 5, France
}

\begin{abstract}
This research aims at improving barrier properties of poly(3-hydroxybutyrate-co-3hydroxyvalerate), PHBV, by incorporating boron nitride particles (BNPs) via melt compounding. To meet this objective, PHBV nanocomposite samples containing different BNPs were prepared and the effects of BN loading and silane surface modifier on the barrier properties of PHBV nanocomposites were investigated. For all the nanocomposite samples, the permeability is decreased in comparison to the neat PHBV due to both the presence of BN particles and a higher crystallinity. The results demonstrate that barrier properties of the composites were found to increase more for the silanized flake type BN (OSFBN) compared to silanized hexagonal disk type BN (OSBN). The best barrier properties are obtained for the nanocomposite sample containing 2 wt. \% OSFBN, for which a reduction of oxygen permeability up to $36 \%$ was observed in comparison to the neat PHBV. Silane-treated BN nanoparticles yielded nanocomposites characterized by good barrier performance and fine BN dispersion, as shown by SEM investigations. The phenomenological gas permeation models were employed to evaluate the effect of BN particles on oxygen transfer properties. The best approach was found for the relative permeation by using Cussler and Lape models.
\end{abstract}

Key words: Biopolymer, bionanocomposite, poly (3-hydroxybutyrate-co-3-hydroxyvalerate), hexagonal boron nitride, gas barrier properties.

"corresponding author

e-mail address:mualloner@gmail.com; oner@yildiz.edu.tr 


\section{Introduction}

In recent years, the use of biopolymers produced from renewable resources has attracted attention for the purpose of reducing the non-degradable polymer wastes. These materials are thought to have an important potential to replace fossil fuel-based polymers. The factors that trigger this replacement are limited fossil fuel resources, high prices of fossil fuels, the effects of fossil fuels on environmental problems such as climate change and global warming and the problem of waste that forms after the use of petroleum-based products. Petro-based polymers, which are trapped in the environment, cause environmental pollution and damage the natural life. Non-biodegradable plastic bags affect the marine ecosystem because of reduced capacities of landfills, and environmental persistence of plastics. In addition, the toxic emissions resulting from the combustion of plastics are also one of the major environmental problems. Replacement between petro-based and bio-based materials will be a big step in reducing $\mathrm{CO}_{2}$ emissions [1-5]. Biodegradable polymers are alternative materials for the solution of environmental problems. Therefore, the innovations in the development of materials from biopolymers will play a more significant role in the future. However, until now, biodegradable polymers have not found a wide industrial application area, because of their high production cost and inadequate performance when compared to petro-based plastics [6-7].

Polyhydroxyalkanoates (PHAs) are a member of the thermoplastic biodegradable polymers family and are particularly attractive due to their environmentally friendly properties such as biodegradability, biocompatibility, renewability and also their good gas barrier properties. PHAs are polyesters of R-hydroxyalkanoic acids and are synthesized from bacteria under nutritionlimited conditions. PHAs are accumulated as gram positive and gram negative bacteria as storage compound. They have thermoplastic properties and can be produced from renewable carbon sources. They release a small amount of carbon dioxide to the environment when they decompose. PHAs attract attention in the industrial field as well as in the research area because of these unique properties [8-11]. Poly (3-hydroxybutyrate-co-3-hydroxyvalerate) (PHBV), a random 3-hydroxybutyrate $(3 \mathrm{HB})$ and 3-hydroxyvalerate (3HV) copolymer which belongs to the PHAs family, has been extensively studied and identified as good candidates to replace fossilbased polymers. It is produced by a wide variety of microorganisms as carbon and energy sources and has been marketed since the early 1980s [12-13]. Degradation of PHBV has been demonstrated under aerobic, anaerobic conditions or composting medium or enzymatic and hydrolytic medium. Because of PHBV's biodegradability and biocompatibility, it can be used in absorbable surgical sutures, biomedical materials, tissue engineering and drug delivery systems. 
PHBV can be made into films, by using different processing methods. PHBVs good gas barrier properties make it a good candidate for the packaging industry. Due to their low gas permeability properties, they increase the shelf life of food materials and delay foods' spoilage [14-17]. To increase the barrier properties of PHBV, different strategies have been suggested such as the use of organic and inorganic nanofillers as reinforcing agents [18]. Hassaini et al. [19] produced PHBV/olive husk flour (OHF) composites using melt blending technique. They investigated the effect of the filler and surface modification on oxygen permeability by using silane-treated and untreated OHF. The results showed that oxygen permeability of biocomposites was lower than neat PHBV and also silane treatment decreased oxygen permeability of the biocomposite by almost 62\% when compared to untreated OHF [19]. Malmir et al. [20] prepared PHBV/cellulose nanocrystal (CNC) composites by solvent casting and improved oxygen barrier properties. Oxygen transmission rate of PHBV was reduced significantly with CNC nanoparticles [20]. Pardo-lbáñez et al. [21] produced PHBV/keratin composites with solution blending technique and investigated barrier properties. The maximum reduction in oxygen permeability was obtained with 1 wt.\% keratin loading. Oxygen permeability is increased due to increased agglomeration at higher loadings [21]. Kovalcik et al. [22] examined the gas barrier properties of $\mathrm{PHBV} /$ lignin composites which were produced with melt compounding technique. Oxygen permeability decreased by $77 \%$ for 1 wt. \% PHBV/lignin composite [22]. Correa et al. [23] combined organomodified montmorillonitride (OMMT) clay with PHBV by using twin screw extruder and internal mixer, and examined their oxygen barrier properties. PHBV and composites were produced with plasticizer and without plasticizer. Plasticizer was used for decreasing the thermo-mechanical degradation of polymer during the extrusion. The results showed that OTR value for all composites decreased when compared to neat polymer [23]. Castro-Mayorga et al. [24] produced PHBV/zinc oxide ( $\mathrm{ZnO})$ composites with melt mixing and electrospinning, and investigated their oxygen barrier properties. Oxygen permeability value decreased due to the interaction of the ZnO particles with the PHBV matrix [24]. AmbrosioMartin et al. [25] studied on PHBV/functionalized graphene sheets (FGS) composites with highenergy ball milling technique and obtained the reduction in oxygen permeability with the addition of FGS [25]. PHBV/bacterial cellulose nanowhiskers (BCNW) nanocomposite was produced by solution casting [26]. They obtained improvement in oxygen permeability with the presence of $1 \%$ BCNW [26]. Öner et al. [27] worked on non-silanized boron nitride/PHBV composite which was produced by the extrusion method. The results showed that with boron nitride addition, the oxygen permeability of composites decreased [27].

There are different kinds of fillers which can be used to produce nanocomposite to improve 
barrier properties of the polymer. Among the most used fillers, two-dimensional (2D) boron nitride crystals have attracted recently a great interest due to their structural similarities to graphene. Boron nitride can exist in many different forms because of the specific bond between boron and nitrogen atoms. Hexagonal boron nitride (h-BN), which is the most known type, is named as white graphite due to the hexagonal structure similar to graphite. $\mathrm{h}$-BN is a filler material which is widely used in nanocomposite production [28-30]. Kisku and Swain [31] produced Chitosan/BN composites by solution method. Significant reduction in the oxygen permeability rate up to $10 \% \mathrm{BN}$ loading was observed. This situation has been interpreted as the slowing of oxygen transmission due to the dispersion of BN into chitosan matrix and formation of tortuous gas permeation pathway [31]. Pradhan et al. [32] investigated the gas barrier properties of starch by combining it with BN with solution technique. The oxygen permeability of starch/BN composites decreased 6 times compared to the pure starch matrix. As a result, a suitable material has been obtained for food packaging applications due to low oxygen permeability [32].

Xie et al.[33] and Lee et al.[34] worked on polyethylene and exfoliated boron nitride composites by using different manufacturing techniques. Poly (ethylene terephthalate) (PET) and exfoliated boron nitride nanosheet composites were produced by melt-processing and their oxygen barrier properties were investigated by Xie et al. [33]. The oxygen permeability of these composites was reduced by $42 \%$ by adding nano-sized $\mathrm{BN}$ at 0.017 vol. $\%$ and $70 \%$ at 3 vol.\% nano-sized BN loading [33]. Lee et al. [34] prepared the polyethylene/exfoliated boron nitride nanoparticles (BNNP) composites by solution mixing and studied their gas barrier properties. The addition of BNNP to the polymer matrix resulted in a $46 \%$ reduction in oxygen permeability [34].

Kwon et al. [35] investigated the oxygen permeability properties of hexagonal boron nitride nanosheet (BNP)/styrene butadiene resin (SBR) composites and comparison of BNP with other fillers. The composites were prepared by Banbury mixer. The lowest oxygen transfer rate (OTR) in the study was obtained in SBR/BNP composites. SBR/BNP nanocomposites showed 35\% improvement compared to composites containing carbon nanotubes (CNT) and 13\% compared to graphite/elastomer composites. These results were attributed to the large layered shape of BNP and its good distribution within the matrix [35]. Bionanocomposites were produced by the solution casting method using boron nitride and cellulose matrix by Swain et al. [36]. The distribution of boron nitride in the matrix decreased the oxygen permeability rate. The oxygen permeability rate of all biocomposites was lower than oxygen permeability rate of pure cellulose, and this decrease was enhanced as the amount of BN increased [36]. The soy protein/boron nitride nanocomposites were prepared by solution method by Dash et al. [37]. The oxygen 
permeability of soybean/BN nanocomposites at constant pressure was studied and the rate of oxygen permeability was found to decrease as the percentage of boron nitride increased. The decrease in oxygen permeability is thought to be due to the microstructural distribution of the boron nitride in the soya protein matrix. The oxygen permeability of soybean/BN nanocomposite was reduced by about six times compared to the soybean matrix [37].

We report here on our continuing study of the improvement of oxygen barrier property of PHBV by incorporating boron nitride particles with a twin screw extruder so that it could be transferred to industry for large scale production. In our previous work, unmodified hexagonal nanoplate BN were studied as potentially interesting material for the enhancement of PHBV properties [27]. Based on our preliminary results indicating the potential of BN to improve the barrier of PHBV matrices, the aim of this work was to further enhancing of the barrier properties by taking into consideration the effect of size, shape, aspect ratio, volume fraction, surface chemistry and dispersion level of the nanoparticles on the barrier properties of biologically relevant PHBV/BN nanocomposites. In order to develop this understanding, polymer nanocomposites containing boron nitride nanoparticles of two different shapes, hexagonal nanoplate (OSBN) and nanoflakes (OSFBN) were prepared through melt processing route with different concentrations to elucidate the role of nanoparticle characteristics on the oxygen barrier properties of the resulting nanocomposites. Improvements in barrier properties of PHBVs will be beneficial for the current applications of packaging of food products and should also lead to applications in pharmaceuticals and electronic packaging which are sensitive to oxygen. PHBV/BN sustainable nanocomposites are very promising to be used as containers for beverage and food products as well as for disposable applications like cutlery or overwrap films. The silane coupling agent, octyltriethoxysilane (OTES) was used for surface modification of boron nitride. The silane coupling agent increases the tendency to bond and affinity between the filler and the matrix, thereby it significantly improves the properties of the composite [38]. Fitment of different barrier models such as Nielsen, Bharadwaj, Cussler, Lape, Gusev-Lusti and Fredrickson-Bicerano with the experimental permeability values was used to evaluate the effect of reinforcement by BN particles on the oxygen barrier of the composites. The results of this research indicate that nanoparticle geometry, dispersion of particles and surface chemistry are important parameters to be considered in designing and characterizing the structure-property relationship in polymer nanocomposites. The best barrier properties are obtained for the nanocomposite sample containing 2 wt.\% the silanized flake type BN (OSFBN) for which a reduction of oxygen permeability up to $36 \%$ was observed in comparison to the neat PHBV. 


\section{Materials and Methods}

\subsection{Materials}

PHBV, the biopolymer with 8 mol\% hydroxyvalerate (HV) content was purchased from ADmajoris Company, France under the trade name MAJ'ECO FN000HA. Two different types of hexagonal nano-sized BN were used. One of the BN's was purchased from Bortek, Turkey (2.27 $\mathrm{g} / \mathrm{cm}^{3}$, surface area $20 \mathrm{~m}^{2} / \mathrm{g}$ ); the other BN (FBN), commercial grade (PHPP325B) $\left(2.2 \mathrm{~g} / \mathrm{cm}^{3}\right.$, surface area $60 \mathrm{~m}^{2} / \mathrm{g}$ ), from Saint-Gobain Ceramics, France. Octyltriethoxysilane (OTES) was provided by Sigma-Aldrich.

\subsection{Surface Modification of BN}

In this work, surface modification of BN crystals is performed using silane coupling agent. The most important factors in the preparation of nanocomposites with good dispersion and desired properties are to obtain nanoparticle dispersions having a homogeneous size distribution and to form a strong interface between the polymer matrix and the nanoparticle. Crystals and other nano-sized particles have a high tendency to come together and agglomerate due to their high adsorption surface energies. Coating the surfaces of crystals and other nanoparticles to be used in nanocomposite formation with an appropriate organic binding agent is an effective method for providing suitable nanophase dispersion in the polymer matrix.

BN nanoparticles were dispersed in ethanol/water solution by sonication in a cup-horn sonicator to reduce the size of nanoparticle aggregates. BN $(1.5 \% \mathrm{w} / \mathrm{v})$ particles were added to the $90: 10$ $(\mathrm{v} / \mathrm{v})$ ethanol-water mixture and treated with an ultrasonic probe system (Sonic vibra cell VCX 750) for $30 \mathrm{~min}$ with an amplitude of $40 \%$. The mixture was then centrifuged (Sigma 3-16P) at 4000 for $35 \mathrm{~min}$ to isolate the stable boron nitride dispersion. Octyltriethoxysilane (OTES) with a concentration of $2.5 \%(\mathrm{w} / \mathrm{v})$ was dissolved in a $90: 10(\mathrm{v} / \mathrm{v})$ ethanol-water mixture and the $\mathrm{pH}$ of the solution was adjusted to 5.0 using dilute $\mathrm{HCl}$ solution [39-40]. The solution was stirred by an ultrasonic mixer for 2 hours at room temperature for silane hydrolysis and BN particles were added to the solution and sonicated with an ultrasonic probe for $30 \mathrm{~min}$ with an amplitude of $40 \%$. The solution was centrifuged at $4000 \mathrm{rpm}$ for $10 \mathrm{~min}$. Finally, the obtained silanized BN was first dried at $110^{\circ} \mathrm{C}$ in an oven for 2 hours and then at $65^{\circ} \mathrm{C}$ for $24 \mathrm{~h}$ in a vacuum drier.

\subsection{Preparation of Nanocomposites}

Composites were prepared by combining the PHBV with BN added at different percentages by melt blending. The polymers and BN were dried in vacuum oven at $50{ }^{\circ} \mathrm{C}$ for $1 \mathrm{~h}$ before 
processing. $30 \mathrm{gr}$ batches according to weight percentages were mix-agitated together before feeding extruder. Extruded neat polymer was designated PHBV. For composite fabrication, different weight ratios of $\mathrm{BN}(0.5,1,2$ and $3 \mathrm{wt} \%)$ was added to the PHBV. For example, in Table 1, PHBV plus 1 percent weight (1wt\%) OSBN was designated PHBV/1OSBN and PHBV plus 1 weight percent (1wt \%) OSFBN was designated PHBV/1OSFBN. The nanocomposites were prepared in a twin screw extruder (Rondol Microlab, England; L/D: 20). Extruder temperatures have been applied $90-135-160-160-150{ }^{\circ} \mathrm{C}$ from the feed section to the end point respectively and worked at a screw speed of $80 \mathrm{rpm}$. The melting temperature during the process is about $160{ }^{\circ} \mathrm{C}$. Polymer films were prepared with hot-cold press machine (Gülnar Makine, Turkey). The thickness of samples for oxygen permeability analysis was approximately $0.75 \mathrm{~mm}$. Table 1 shows the prepared nanocomposites. OS code shows silanized samples.

Table 1. Codes of composites

\subsection{Characterization of BN Nanoparticles and Composites}

\subsubsection{Scanning Electron Microscopy (SEM)}

Morphologies of BN samples were obtained by scanning electron microscopy (FEI-Philips XL 30 ESEM-FEG). We examined different SEM micrographs of the same sample and the dimensions of the particles were obtained using the Image $\mathrm{J}$ program. The dimensions of minimum of 100 crystals in each sample were measured from SEM photomicrographs and performed statistical analysis on the products. The cryogenically fractured surface of composites was analyzed in the SEM.

\subsubsection{BET analysis}

BET (Brunauer-Emmett-Teller) analysis was performed to determine the specific surface area value of the particles. The device which used for analysis was the Quantachorome Quadrosorb SI. Outgas temperature was $300^{\circ} \mathrm{C}$ and the duration was 16 hours.

\subsubsection{X-ray Diffraction (XRD)}

The crystalline structure of the nanocomposites was examined by X-ray diffraction (XRD) equipment (PHILIPS diffractometer X'pert Pro (Pan Analytical)) with $\mathrm{Cu}$ Ka radiation (wavelength of $1.54 \AA$ ) for a $2 \theta$ range from $10^{\circ}$ to $80^{\circ}(40 \mathrm{kV}, 20 \mathrm{~mA})$. Crystal size is calculated according to Sherrer Equation [41]:

$D=\frac{k \lambda}{\beta \cos \theta}$ 
$D=$ The crystal size $\left(A^{\circ}\right)$

$k=$ The shape factor $(=0.9)$

$\beta=$ The full width at half maximum of the diffraction peak (FWHM)

$\lambda=$ The $\mathrm{X}$-ray wavelength $\left(=1.54 \mathrm{~A}^{\circ}\right)$

$\theta=$ The diffraction angle

The FWHM values of the samples are calculated using the XRDA program.

\subsubsection{Oxygen Transmission Rate (OTR)}

Systech Model 8001 Model Oxygen Permeation Analyzer was used for analysis of the Oxygen transmission rates (OTR) of neat PHBV and PHBV/BN composites films. The samples were cut at appropriate dimensions and oxygen permeability was measured according to ASTM D398505 standard. Measurements were carried out in $8 \mathrm{~cm}$ diameter area and mask was not used during measurement. The tests were conducted at $23^{\circ} \mathrm{C}, 0 \%$ relative humidity and $1 \mathrm{~atm}$ pressure with highly purified oxygen (99.99\%) and nitrogen (99.99\%) gases. Tests were stopped when OTR graphics showed the steady condition. The permeability (OP) was calculated by multiplying the measured steady state transmission rate by the average sample thickness. At least two separate films were measured for each sample.

\section{Results and Discussion}

\subsection{Morphology of BN nanoparticles}

In this study, SEM analysis of two different types of boron nitrides was performed in order to determine the morphology and size of the BN particles. SEM images of untreated BN (a), ultrasonicated and silanized OSBN (b), untreated FBN (c) and ultrasonicated and silane treated OSFBN (d) particles are shown in Figures 1. As observed by SEM, the shape of the OSBN nanoparticles was a nearly hexagonal disk with an aspect ratio of approximately 4.1 . The OSFBN nanoparticles showed irregular flake-like shapes with the mean aspect ratio of 18.9. The aspect ratio was calculated from the particle size measurement done on the SEM images. In order to compare the particle sizes obtained prior to composite processing, the dimensions of both BN nanoparticles were measured using SEM images. The dimensions of 100-150 particles in each sample were measured taking at least six different SEM images for each type of boron nitride by using Image $\mathrm{J}$ programme and performed statistical analysis on the products. The range of values calculated from SEM was on the order of hundreds of nanometers, indicating that each particle system was polydisperse. The results show that the size of the OSBN with 
ultrasonic treatment for 60 minutes was somewhat reduced and especially for the OSFBN, agglomeration was broken as a result of ultrasonication and the boron nitride layers were partially exfoliated. The mean length $(\mathrm{L})$, the mean width $(\mathrm{w})$ and thickness $(\mathrm{t})$ of the OSFBN particles were reduced from $2445.9 \pm 1507.6 \mathrm{~nm}$ to $765.4 \pm 376.8 \mathrm{~nm}$; from $1483.7 \pm 853.8 \mathrm{~nm}$ to $360.49 \pm 177.8 \mathrm{~nm}$ and from $249.7 \pm 137.4 \mathrm{~nm}$ to $19.0 \pm 5.1 \mathrm{~nm}$, respectively. The mean diameter (d) and thickness (t) of OSBN particles, reduced from $225.0 \pm 108.0 \mathrm{~nm}$ to $163.3 \pm 72.9 \mathrm{~nm}$ and from $61.6 \pm 25.8 \mathrm{~nm}$ to $39.7 \pm 10.7 \mathrm{~nm}$, respectively after ultrasonication. As can be seen in the figures treated boron nitride particles are well dispersed compared to untreated particles. Nanocomposites which contain well dispersed nanoscale filler are advantageous because of more powerful interaction between filler and polymer.

Figure 2 illustrates the XRD patterns of nonsilanized and silanized boron nitrides particles. The results of the diffractograms showed that the relative peak intensity of the (002) plane is found to decrease after silanization. Generally, the sharpness and intensity of XRD peaks are regarded as proportional to crystallinity. Thus, we can say that surface treatment of BN particle with silane coupling agent reduces its crystallinity degree. Similar result was also observed by Pineda et al.[42]. They found that the the silanization process rendered hydroxyapatite with lower crystallinity compared to untreated hydroxyapatite.

The BET analysis of the particles showed that the surface area of the OSBN and OSFBN particles was increased from $20 \mathrm{~m}^{2} / \mathrm{g}$ to $26.89 \mathrm{~m}^{2} / \mathrm{g}$ and from $60 \mathrm{~m}^{2} / \mathrm{g}$ to $71.9 \mathrm{~m}^{2} / \mathrm{g}$ respectively, as a result of the decreasing of the particle size of $\mathrm{BN}$ after 60 minutes of ultrasonic treatment.

\section{Figure 1.}

Figure 2.

\subsection{SEM of nanocomposites}

OSBN and OSFBN particles were used to produce nanocomposites at different BN loadings. The dispersion of the BN particles achieved in PHBV matrix was observed using SEM. Figure 3a-b show SEM photographs for the PHBV/1OSBN and PHBV/1OSFBN composites. The nanoparticles appeared uniformly dispersed and distributed in the PHBV matrix at $1 \mathrm{wt} \% \mathrm{BN}$ concentration. The edges of individual particles are visible at the fracture surface, and no particle aggregates were observed. The aggregates of particles that were observed in the SEM at $3 \mathrm{wt} \%$ 
OSFBN (Figure 3c). The highest loading did not display well dispersed nanoparticles and a few small clusters composed of several particles can be observed. This phenomena give rise to some disorders in polymer nanocomposites and could be a reason of decrease of crystallinity and barrier properties. The SEM picture of the composite prepared by using nonsilanized boron nitride (PHBV/1FBN) is given in Figure 3d. Scanning electron micrographs of the composites without silane modification showed many holes. Composite with surface modification showed better adhesion between BN and polymer matrix (Figure $3 \mathrm{~b}$ ). This result showes that silanization has a strong effect on bonding of filler to polymer matrice. The incompatibility between nanoparticles and polymer matrix is usually a challenge and it may lead to particle agglomeration and void formation in the composites. A sufficient interfacial adhesion between the particle and the polymer is an important requirement for nanocomposites. In this work we used silane coupling agent in order to improve BNs interaction with the PHBV matrix.

\section{Figure 3.}

\subsection{XRD Results}

In order to observe any changes to the crystalline structure of PHBV in presence of hexagonal plates and flakes nanoparticles, X-ray diffraction (XRD) was performed on neat PHBV and both PHBV/OSBN and PHBV/OSFBN nanocomposite samples. Figure 4 shows the XRD patterns of neat PHBV, PHBV/OSBN and PHBV/OSFBN nanocomposites along with the diffraction patterns of pristine OSBN and OSFBN nanoparticles in the range of 10 to $80^{\circ}$. The main $2 \theta$ values of PHBV correspond to $13.6^{\circ}(020), 17.1^{\circ}(110), 19.9^{\circ}(021) 21.7^{\circ}(101), 22.3^{\circ}(111), 25.5^{\circ}(121)$, $27.1^{\circ}(040), 30.3^{\circ}(002)[43-44]$. The peak at $2 \theta=26.80^{\circ}, 2 \theta=41.69^{\circ}, 2 \theta=43.91^{\circ}, 2 \theta=50^{\circ}$ and $2 \theta=55.12^{\circ}$ corresponding to the (002), (100), (101), (102) and (004) planes of the $h-B N$, respectively [45]. It can be observed that the peak positions for (020), (110) and (002) diffraction planes of the polymer crystals remain unchanged in the XRD patterns of PHBV/BN nanocomposites (Figure 4). This suggests that the crystalline lattice of the PHBV polymer does not change appreciably in the presence of $\mathrm{BN}$.

\section{Figure 4.}

Table 2 and 3 give the effect of the addition of $B N$ nanoparticles on the full width half maximum (FWHM), $d\left({ }^{\circ} \mathrm{A}\right)$ and crystalline size for $(020)$ and (110) reflections of PHBV polymer. $d\left({ }^{\circ} \mathrm{A}\right)$ values of nanocomposites were calculated by using Bragg equation, the crystallite sizes D (nm) was calculated by using Scherrer equation. Both neat PHBV and PHBV/BN nanocomposites have nearly same $d\left({ }^{\circ} \mathrm{A}\right)$ values. This result indicates that $\mathrm{BN}$ addition does not affect the unit 
cell of PHBV [46-47]. The changes in FWHM of (020) peak for PHBV/OSBN and PHBV/OSFBN nanocomposites compared to neat PHBV indicated that the peaks were mostly sharper compared to neat PHBV up to $2 \%$ BN content.

\section{Table 2.}

\section{Table 3.}

The crystallite size for the direction normal to (020) and (110) planes was calculated using Scherrer's equation. Crystallite lamelle sizes $(\mathrm{D}, \mathrm{nm})$ for the $(020)$ direction are higher than the neat polymer for nanocomposites prepared with BN up to $2 \mathrm{wt}$ \%. The crystallite size D [nm] calculated for the (020) reflection peak using Scherrer's equation is 30.77 and $32.0 \mathrm{~nm}$ in neat PHBV and PHBV/2OSFBN nanocomposite respectively. This increase in the crystallite size of (020) crystal plane with BN shows that nanoparticles provoke the increase in the degree of crystallinity. The narrow peak and the rise in the crystallite size of (020) crystal plane of PHBV crystals in the PHBV/BN composites indicate the crystallite growth of PHBV along that direction. However, 3 wt\% addition of boron nitride results in higher FWHM and lower D value than neat polymer. Some variations in the crystallite size with nanoparticle concentration were also seen for the (110) reflection. A decrease in the crystallite size normal to planes has been observed for the (110) reflection. The similar phenomenon was previously observed for PHBV nanocomposites with cellulose nanocrystal-silver nanohybrid [39], multi-walled carbon nanotube [48] and $\mathrm{ZnO}$ [49] fillers.

The bulk polymer matrix morphology in a nanocomposite is one possible material parameter that can influence the barrier efficacy of nanoparticles and hence properties of the resulting nanocomposites. In the case of a semicrystalline polymer matrix composite, the nanoparticles can cause changes in both the amorphous and crystalline phases by restricting the mobility of amorphous polymer chains or by inducing changes in crystal phases, crystallinity or crystal size. For this purpose, the crystallinity indices from XRD measurement was calculated for composites samples and given in Table 4.

Crystallinity index $(C l)$ values were calculated based on the $(020)$ peak of PHBV. The following formula was used for calculating $\mathrm{Cl}$ [50]:

$C I=\frac{I_{(020)}}{I_{\text {Total }}} \times 100$ 
$\mathrm{Cl}$ results have shown that the $\mathrm{BN}$ addition affects the crystallinity of PHBV. The highest crystallinity index values were obtained at filler loadings of $2 \mathrm{wt}$. \% and $1 \mathrm{wt}$. \% BN for PHBV/2OSBN and PHBV/1OSFBN composites respectively as can be seen in Table 4. The crystallinity indices of $1 \mathrm{wt}$. \% nonsilanized and silanized composites are 47.7 and 53.2 for PHBV/1BN and PHBV/1OSBN. The crystallinity indices of composites increases from 42.6 to 62.6 for PHBV/1FBN and PHBV/1OSFBN respectively. However, $\mathrm{Cl}$ values are higher for PHBV/OSFBN composites compare to PHBV/OSBN. This may be related to the higher surface area displayed by OSFBN $\left(71.9 \mathrm{~m}^{2} / \mathrm{g}\right)$ which can promote a better intercalation of BN nanosheets between PHBV chains and influence the polymer chain organization. The BN is known to behave as a nucleating agent and increases the crystallinity of the polymer matrix. The incorporation of $\mathrm{BN}$ is thus increasing the crystallinity index of the PHBV as found by the XRD.

\section{Table 4.}

\subsection{Oxygen Barrier Properties of the Composites}

Oxygen transmission rates (OTR) through PHBV and PHBV/BN composites were measured using an oxygen permeation analyzer. The relationship between OTR and oxygen permeability $(\mathrm{OP})$ were given by the following equation:

$O P=O T R \cdot L / \Delta P$

where OP is the oxygen permeability coefficient $\left(\mathrm{cc} \cdot \mathrm{mm} \cdot \mathrm{m}^{-2} \cdot \mathrm{day}^{-1} \mathrm{~atm}^{-1}\right)$, OTR is the oxygen transmission rate $\left(\mathrm{cc}^{-m^{-2}} \cdot\right.$ day $\left.^{-1}\right), L$ is the film thickness $(\mathrm{mm})$ and $\Delta P$ is the difference (atm) between oxygen partial pressure across the film. Figure 5 and Figure 6 shows the $\mathrm{O}_{2}$ permeability results for OSBN and OSFBN filled composites respectively as a function of the BN composition.

\section{Figure 5.}

\section{Figure 6.}

As can be seen in Figure 5 and 6, the oxygen permeability for the composites has been decreased in comparison with neat PHBV. For instance, permeability of $\mathrm{O}_{2}$ at $23{ }^{\circ} \mathrm{C}$ decreases from 1.32 (cc.mm. $\mathrm{m}^{-2} \cdot \mathrm{day}^{-1} \mathrm{~atm}^{-1}$ ) in PHBV to 0.84 (cc.mm. $\mathrm{m}^{-2}$. day ${ }^{-1} \mathrm{~atm}^{-1}$ ) in PHBV/2OSFBN nanocomposites. The OP of PHBV reduced to 0.97 (cc.mm. $\mathrm{m}^{-2}$. day ${ }^{-1} \mathrm{~atm}^{-1}$ ) for PHBV/1OSBN. Oxygen barrier properties improved by $36.4 \%$ with $2 \%$ wt. of BN for PHBV/2OSFBN and $26.4 \%$ 
with 1 wt. \% of BN for PHBV/1OSBN but do not improve with further increasing the BN content. Oxygen permeability values showed increase for both $3 \%$ wt OSBN and OSFBN contents. This result shows that BN filler particles were well dispersed at low filler loadings but nonhomogenously distributed at higher concentrations. These findings are in agreement with the XRD results. As can be seen in Table 4, $\mathrm{Cl}$ values drop at 3 wt.\% loadings. Boron nitride has homogeneously dispersed in PHBV matrix below 3 wt.\% loadings and promoted the crystallization. This result associated to XRD analyses shows that BN filler particles at low filler loadings directly influence the morphological organization of PHBV polymer matrix by increasing the crystallinity (Table 4) and reducing the oxygen permeability (Figure 7). However, the effect of nanoparticles addition is not linear and above a certain limit there is a reduction of crystallinity enhancement. By considering only the results on crystallinity, this threshold is above 2 wt. \% for OSFBN and $1 \mathrm{wt}$ \% for OSBN. It can be assumed that the nanoparticles are non-homogenously distributed at higher concentrations. OSBN-PHBV or OSFBN-PHBV interactions are probably weaker compared to Van der Waals bonds between boron nitride nanosheets which may lead to the agglomerate formation at higher BN filler concentrations. These agglomerates would reduce the ability of BN particles to act as nucleating agent and thus would decrease the crystalline area of the polymer matrix. It is generally assumed that gas molecules can diffuse through free volumes at the amorphous phase of a semi-crystalline material and no gas diffusion takes place in the crystalline phase [51-52]. Therefore, a decrease in gas diffusion is expected with increasing crystallinity.

\section{Figure 7.}

In order to see surface functionalization on barrier properties, the composite samples were prepared without using coupling agent. The OP values of nonsilanized nanocomposites with 1 wt.\% BN and 1 wt.\% FBN content are 1.11 and 1.04 (cc.mm. $\mathrm{m}^{-2}$.day ${ }^{-1} \mathrm{~atm}^{-1}$ ), respectively. After silanization the OP values decreased to 0.97 and 0.87 (cc.mm.m ${ }^{-2} \cdot$ day $^{-1} \mathrm{~atm}^{-1}$ ), for OSBN and OSFBN nanocomposites respectively. The results show that silanization resulted in improvement of the oxygen permeability of the composites. Silanization reduces the surface energy of BN particles and thus improve its dispersion in the matrix material. The silane coupling agent can act as 'bridge linkage' to connect BN and polymer matrix, further improving the interfacial bonding strength of the composites.

\subsection{Gas Permeability Models}

The gas permeability models have been developed to explain the mechanism of the permeability 
of polymer nanocomposites by considering the morphology of nanoparticles such as aspect ratio, array, orientation and also considering volume fraction of nanoparticles, nanoparticlepolymer interaction and polymer structure. Most of the models were built upon the tortuous path theory, which is mainly based on the general assumptions that nanofillers are impermeable to gas molecules. The fillers increase the barriers properties of polymers by creating a maze or tortuous path that retards the diffusion of gas molecules through the polymer matrix. The tortuosity factor is affected by the aspect ratio of particles dispersed in the matrix. Some of the models and corresponding equations are given in Table 5. In these models $\alpha$ represents aspect ratio and $\Phi$ symbolizes the volume fraction of nanoparticle in composite, is defined as [53]:

$\phi=\frac{\left(M_{p} / \rho_{p}\right)}{\left(M_{m} / \rho_{m}\right) /\left(M_{p} / \rho_{p}\right)}$

$M_{p}$ and $\rho_{p}, M_{m}$ and $\rho_{m}$ are the molecular weight and density of particle and the molecular weight and density of polymer matrix, respectively.

\section{Table 5.}

The permeation of gases through mineral-filled polymers was first dealt in model by Nielsen in 1967. Later on, different models have been used to predict gas permeations properties of polymer composites. Nielsen Model is one of the simplest model assumes that the barrier layers consist of ribbons and are assumed to be perfectly dispersed and aligned in the matrix. An increase in the tortuosity results from the aspect ratio $\alpha$ of layered ribbons. The analytical solution provided by Nielsen was further compared with simulation techniques and more refined expression was predicted. Cussler proposed phenomenological models for gaseous diffusion in the polymer matrix, considering the polydispersity effects in the matrix and the randomness of the arrangement of the flake-like structures in the matrix. Lape model accounted for the polydispersity effects of the flake dimensions in the matrix and incorporated the randomness of arrangement of the flake-like structures in the matrix [54]. Bharadwaj modified the Nielsen model to predict gas barrier in the case of randomly dispersed fillers by considering the orientation parameters S, in which the direction of the solute molecule to layers [55]. In Cussler and Nielsen models, it is assumed that solute molecule diffuse perpendicular to nanofiller $(S=1)$. However, Bharadwaj considered the effect of diffusion direction and derived a new model equation for random platelet orientation $(S=0)$ [55]. The diffusion in nanocomposites containing oriented and randomly arrayed 3D disk shape particles were molded by both Fredrickson and Bicerano, and 
Gusev and Lusti based on a second-order approximation from multiple scattering formulations and finite element calculation, respectively [55-57].

The experimental permeability data obtained for the different nanocomposites were compared to the relative permeabilities predicted by the models. Most of the models were not able to match the data over at least part of the composition range explored here. The calculated aspect ratio from the models varied from 30 to 250, however, as we have observed in SEM images, the aspect ratio for OSFBN flakes should be around 19 and for OSBN disks be around 4. Our modeling results showed that Cussler's random array and Lape models give more realistic phenomenological fitting for those complex systems. Therefore, the models exhibiting the best fit to our experimental data have been drawn in Figures 8 and 9. These figures show the experimental and predicted values for oxygen relative permeability $\left(R_{p}=O P / O P_{0}\right)$. These values were calculated by substituting the known values in the models and were plotted as a function of volume fraction for different aspect ratio $(\alpha)$ of $\mathrm{BN}$.

\section{Figure 8.}

\section{Figure 9.}

Table 6 compares the aspect ratios predicted by the permeability models with those observed from SEM images. Table 7 lists the percent deviation between the observed and the predicted values of relative permeabilities as suggested by the models.

\section{Table 6.}

\section{Table 7.}

The experimental and predicted values for $R_{p}$ match closely at the aspect ratio of 40 for OSBN composites and aspect ratio of 60 for the OSFBN composites for Cussler model. Similarly, the actual and predicted values for $R_{p}$ match closely at the aspect ratio of 30 for the OSBN and aspect ratio of 40 for the OSBN composites for Lape model. The models predict higher aspect ratio for the nanocomposites than observed in SEM images of particles. It is worth noting that the most of the models employed here developed for clay particles with high aspect ratios and only considering the available surface or effective gas permeation with complete exfoliation 
assumption. The factors such as polymer-particle interaction, crystallinity and solubility of the permeating substance are not taken into consideration [56].

\section{Conclusions}

In this study, PHBV/BN biocomposites with various loadings of $\mathrm{BN}$ were fabricated using extrusion processing. Silane modified $\mathrm{BN}$ has been shown to contribute to a greater enhancement of barrier properties than unmodified BN. Silane coupling agent can improve the bonding of PHBV/BN and enhance its barrier properties. Silane modified BN can be uniformly dispersed in the matrix and produce the barrier effect when appropriate addition. XRD results revealed that crystallinity of the matrix increases with $\mathrm{BN}$ addition. It was found that the gas barrier properties of nanocomposites were improved by a good distribution of BN particles within the matrix. The barrier properties of the films containing silane surface agent are better than those without the surface agent, which can be attributed to the better BN distribution. The best BN distribution and barrier properties were obtained for OSFBN. Overall, a $36 \%$ improvement in barrier properties was obtained for the PHBV nanocomposites containing OSFBN in comparison to the neat PHBV sample. According to XRD, and SEM results, the OSFBN samples show the highest level of aspect ratio and the highest level of crystallinity which explains the lowest oxygen permeability. The deviations were observed between experimental and predicted aspect ratio of the particles with various models. Cussler and Lape models give the best approach for relative permeation values. This work suggested that characteristics of each type of BN particles in the PHBV/BN composites can be manipulated and designed to enhance the barrier properties.

\section{Acknowledgements}

M.Öner thanks the Scientific and Technological Research Council of Turkey (TÜBITAK, Project No: 215M355), and M. Bechelany thanks the Campus France (PHC Bosphore No: 35211XD) for funding this work under a Bilateral Cooperation Program between Turkey and France. G. Keskin and G. Kızıl gratefully acknowledge TÜBITAK for a scholarship. 


\section{REFERENCES}

1. I. Vroman, L. Tighzert, Materials, 2, 307 (2009).

2. S. Chabba, G.F. Matthews, A.N. Netravali, Green Chemistry, 7, 576 (2005).

3. W. Smitthipong, R. Chollakup, M. Nardin, Biobased Composites for High-performance Materials, CRC Press,Taylor \& Francis Group, New York (2015).

4. A.A. Kumar, K. Karthick, K.P. Arumugam, Int. J. Biochem. Bioinforma., 1, 173 (2011).

5. S. Kabasci, Bio-Based Plastics Materials and Applications, Wiley, New York (2014)

6. K. Van de Velde, P. Kiekens, Polym. Testing, 21, 433 (2002).

7. A. K. Mohanty, M. Misra, and G. Hinrichsen, Macromol. Mater. Eng., 276, 1 (2000).

8. S. Philip, T. Keshavarz, I. Roy,Journal of Chemical Technology and Biotechnology, 82, 233 (2007).

9. E. Bugnicourt, P. Cinelli, A. Lazzeri, and V. Alvarez, Express Polym. Lett., 8, 791 (2014).

10. G.-Q. Chen, Chem. Soc. Rev. 38, 2434 (2009).

11. A. Kin-Tak Lau, F. Hussain, K. Lafdi, Nano and Biocomposites, CRC Press, Taylor and Francis Group, New York, (2010).

12. Y. Ke, Z. Qu, G. Wu, Y. Wang, Polym. Degrad. Stab.,105, 59 (2014).

13. D. Jun, Z. Guomin, P. Mingzhu, Z. Leilei, L. Dagang, and Z. Rui, Carbohydr. Polym., 168, 255 (2017).

14. M. Koller, Appl. Food Biotechnol., 1, 1 (2014).

15. J. Vartiainen, M. Vähä-nissi, A. Harlin, Mater. Sci. Appl., 5, 708 (2014).

16. C.R. Hankermeyer, C. R. S. Tjeerdema, In Rev. Environ. Contam. Toxicol., 159, 1 (1999).

17. M. Erceg, T. Kovačić, I. Klarić, Thermochim. Acta., 485, 26 (2009).

18. X.Z. Tang, P. Kumar, S. Alavi, K.P. Sandeep, Crit. Rev. Food Sci. Nutr., 52, 426 (2012).

19. L. Hassaini, M. Kaci, N. Touati, I. Pillin, A. Kervoelen, S. Bruzaud, Polym. Test., 59, 430 (2017).

20. S. Malmir, B. Montero, M. Rico, L. Barral, R. Bouza, Compos. Part A Appl. Sci. Manuf., 93, 41 (2017).

21. P. Pardo-lbáñez, A. Lopez-Rubio, M. Martínez-Sanz, L. Cabedo, J.M. Lagaron, J. Appl. Polym. Sci., 131, 1 (2014).

22. A. Kovalcik, M. Machovsky, Z. Kozakova, M. Koller, React. Funct. Polym., 94, 25 (2015). 
23. M.C. Branciforti, M.C.S. Corrêa, E. Pollet, J.A.M. Agnelli, P.A.D.P. Nascente, L. Avérous, Polym. Test., 32, 1253 (2013).

24. J.L. Castro-Mayorga, M.J. Fabra, A.M. Pourrahimi, R.T. Olsson, J.M. Lagaron, Food Bioprod Process., 101, 32 (2017).

25. Ambrosio-Martín, G. Gorrasi, A. Lopez-Rubio, M.J. Fabra, L.C. Mas, M.A. López-Manchado, J.M. Lagaron, J. Appl. Polym. Sci., 132, 1 (2015).

26. M. Martínez-Sanz, M. Villano, C. Oliveira, M.G.E. Albuquerque, M. Majone, M. Reis, A. Lopez-Rubio, J.M. Lagaron, N. Biotechnol., 31, 364 (2014).

27. M. Öner, A.A. Çöl, C. Pochat-Bohatier, M. Bechelany, RSC Adv., 6, 90973 (2016).

28. N.D. Zhigadlo, J. Cryst. Growth., 402, 308 (2014).

29. W. Han, Nanotechnologies for Life Sciences, 3, 411 (2010).

30. X.Fen-Jiang, Q.Weng, X.B. Wang, X.Li, J. Zhang, D. Goldberg, Y. Bando, J.of Materials Science and Technology, 31, 5789 (2015)

31. S.K. Kisku, S.K. Swain, J. Am. Ceram. Soc., 95, 2753 (2012).

32. G.C. Pradhan, L. Behera, S.K. Swain, Chinese J. Polym. Sci., 32, 1311 (2014).

33. S. Xie, O.M. Istrate, P. May, S. Barwich, A.P. Bell, U. Khan, J.N. Coleman, Nanoscale., 7, 4443 (2015).

34. D. Lee, B. Lee, K.H. Park, H.J. Ryu, S. Jeon, S.H. Hong, Nano Lett., 15, 1238 (2015).

35. O.-S. Kwon, D. Lee, S.P. Lee, Y.G. Kang, N.C. Kim, S.H. Song, RSC Adv., 6, 59970 (2016).

36. S.K. Swain, S. Dash, C. Behera, S.K. Kisku, L. Behera, Carbohydr. Polym., 95, 728 (2013).

37. S. Dash, S.K. Swain, Compos. Sci. Technol., 84, 39 (2013).

38. C. Kizilkaya, Y. Mülazim, M.V. Kahraman, N.K Apohan, A. Güngör, J. Appl. Polym. Sci.,, 124, 706 (2012).

39. T. Qi, Y. Li, Y. Cheng, F. Xiao, Proc. Electron. Packag. Technol. Conf. EPTC, 405 (2014)

40. M. Munaro, L. Akcelrud, Polym. Degrad. Stab., 93, 43 (2008).

41. W. Zhou, J. Zuo, X. Zhang, a. Zhou, J. Compos. Mater., 48, 257 (2014)

42. OG. Cisneros Pineda, W.H.Kao, M.I.L.Bastarrachea, V.Y. Pantoja, J.V.C. Rodriguez, J.M. Cervantes-Uc, Mater. Sci. Eng. C Mater Biol Appl.,40, 157, (2014).

43. M. Munaro, L. Akcelrud, Polym. Degrad. Stab., 93, 43 (2008).

44. H. Yu, B. Sun, D. Zhang, G. Chen, X. Yang, J. Yao, J. Mater. Chem. B., 2, 8479 (2014).

45. W. Huang, Y. Wang, L. Ren, C. Du, X. Shi, Mater. Sci. Eng. C., 29, 2221 (2009).

46. J. Biscarat, M. Bechelany, C. Pochat-Bohatier, P. Miele, Nanoscale., 7, 613 (2015). 
47. L.N. Carli, J.S. Crespo, R.S. Mauler, Compos. Part A Appl. Sci. Manuf. , 42, 1601 (2011).

48. G.F. Shan, X. Gong, W.P. Chen, L. Chen, M.F. Zhu, Colloid Polym. Sci. , 289, 1005 (2011).

49. H.Y. Yu, Z.Y. Qin, B. Sun, X.G. Yang, J.M. Yao, Compos. Sci. Technol., 94, 96 (2014).

50. A.M. Díez-Pascual, A.L. Díez-Vicente, ACS Appl. Mater. Interfaces, 6, 9822 (2014).

51. S. Luo, J. Cao, A.G. McDonald, ACS Sustain. Chem. Eng., 4, 3465 (2016).

52. S. Vidhate, L. Innocentini-Mei, N. A. D'Souza, Polym. Eng. Sci., 52, 1367 (2012).

51. L. Sun, W.J. Boo, A. Clearfield, H.J. Sue, H.Q. Pham, J. Memb. Sci., 318, 129 (2008).

53. G.A. Martinez-Hermosilla, B. Mesic, J.E. Bronlund, Packag. Technol. Sci., 28, 565 (2015).

54. M. Bhattacharya, S. Biswas, A.K. Bhowmick, Polymer, 52, 1562 (2011).

55. A. Al-Abduljabbar, J. Nano Res, 29, 75 (2014).

56. Y.H. Seo, C.G. Kang, J. Mater. Process. Tech., 55, 370 (1995).

57. O. Ozcalik, F. Tihminlioglu, J. Food Eng., 114, 505 (2013). 


\section{Figure Captions}

Figure 1. SEM micrograph of boron nitride particles: untreated BN (a), treated OSBN (b) untreated FBN (c) treated OSFBN (d)

Figure 2. XRD patterns of boron nitride particles: untreated BN, treated OSBN, untreated FBN treated OSFBN

Figure 3. SEM photos of composites :PHBV/1OSBN (a), PHBV/1OSFBN (b), PHBV/3OSFBN (c) and PHBV/1FBN (d)

Figure 4. XRD patterns of neat PHBV, BN, FBN and PHBV/silanized boron nitride nanocomposites

Figure 5. OP values of OSBN nanocomposites

Figure 6. OP values of OSFBN nanocomposites

Figure 7. Variation of OP with crystallinity index

Figure 8. Comparison between experimental data with predicted relative permeability value for Cussler model OSBN and OSFBN composites

Figure 9. Comparison between experimental data with predicted relative permeability value for Lape model OSBN and OSFBN composites 


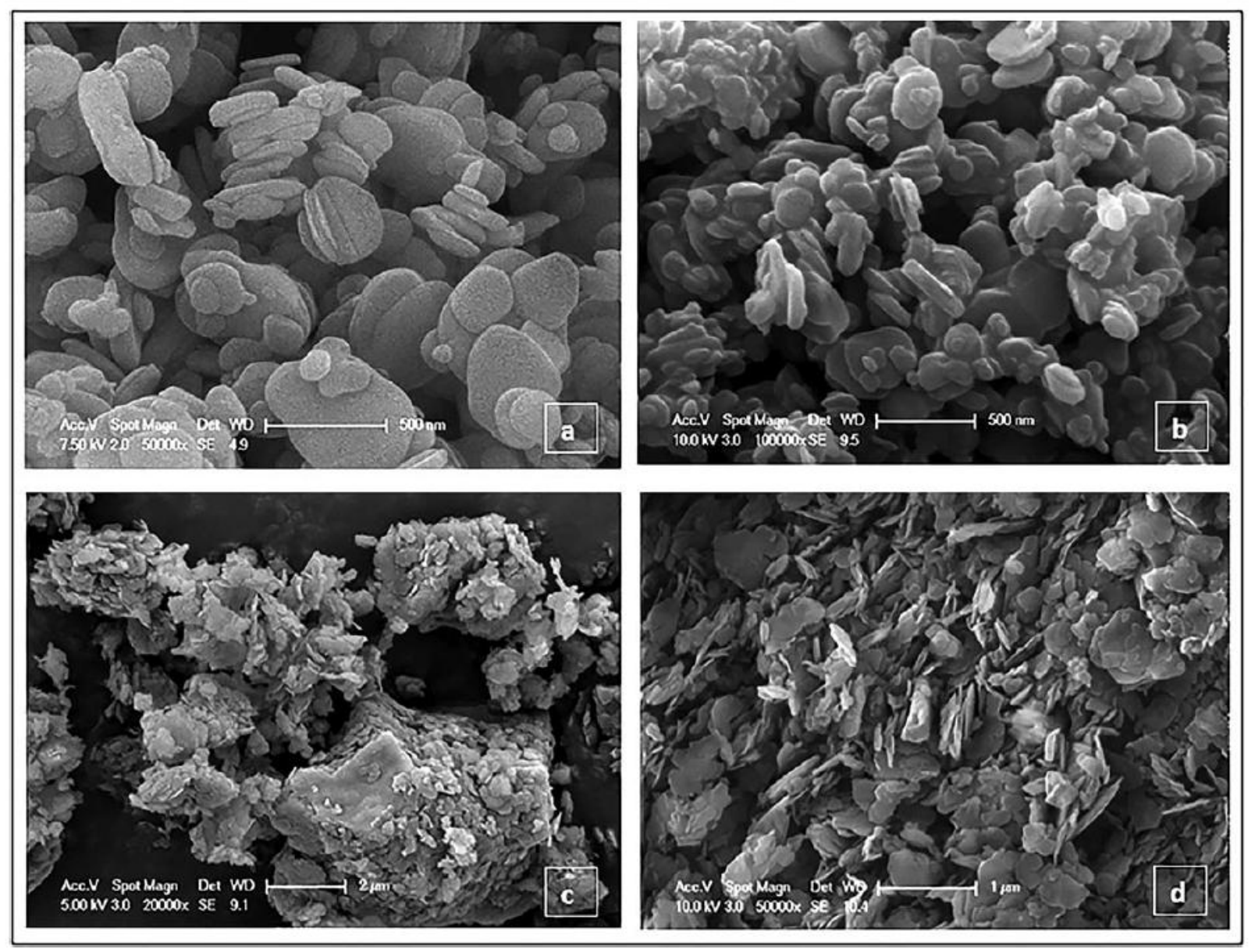

Figure 1
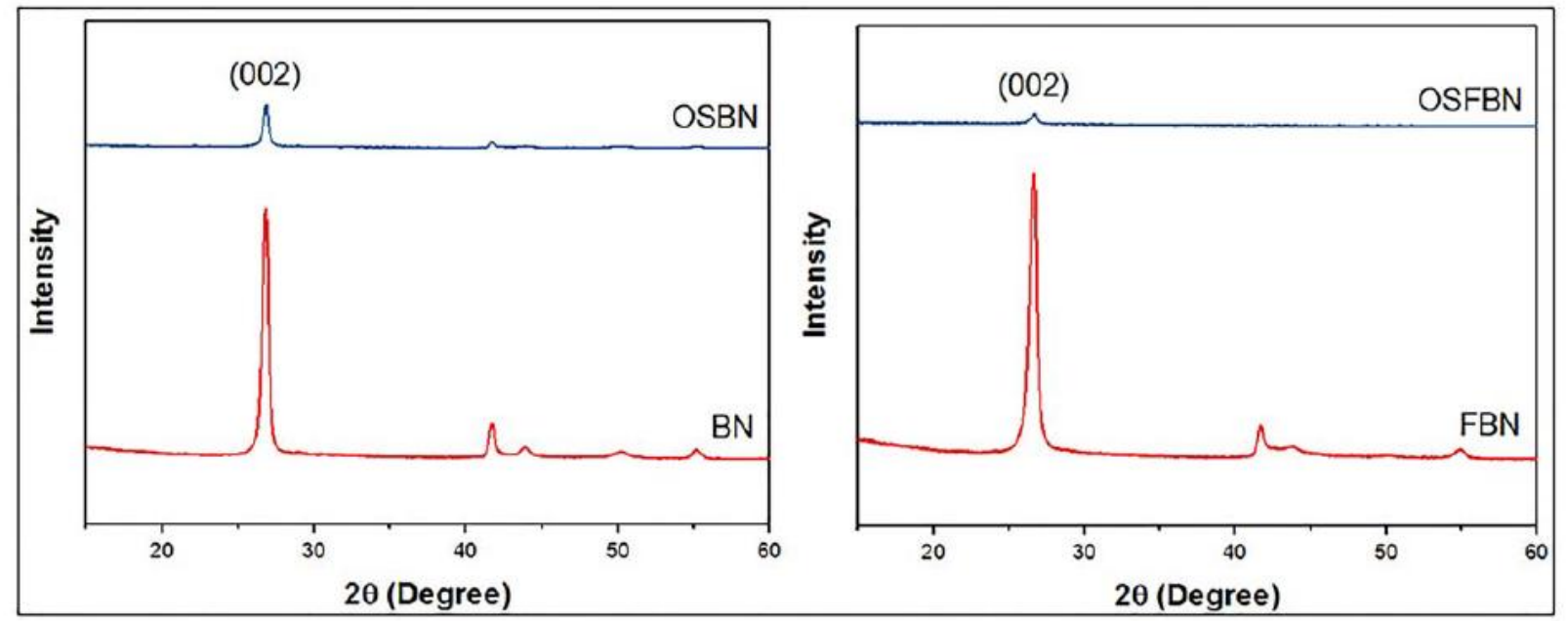

Figure 2 

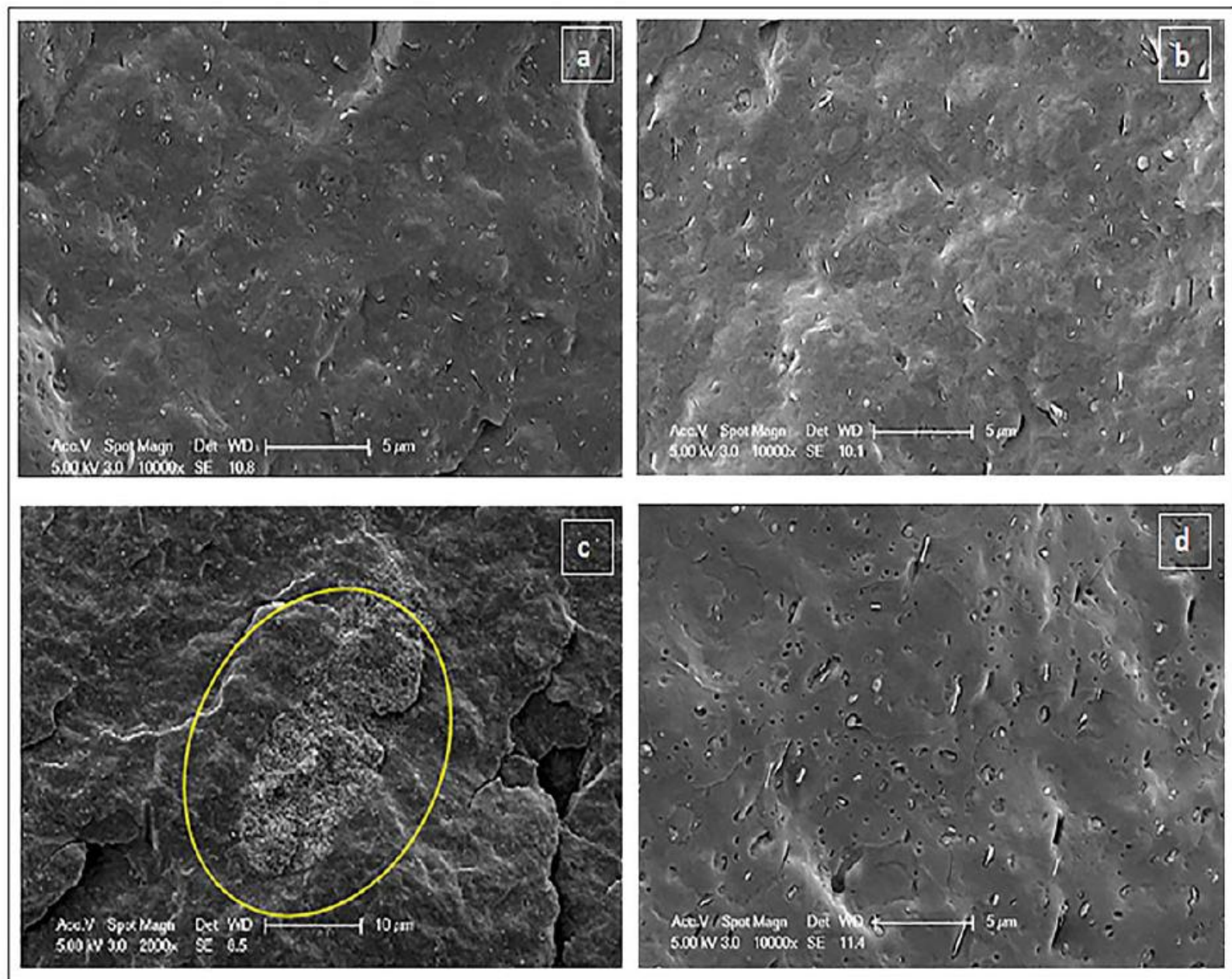

Figure 3

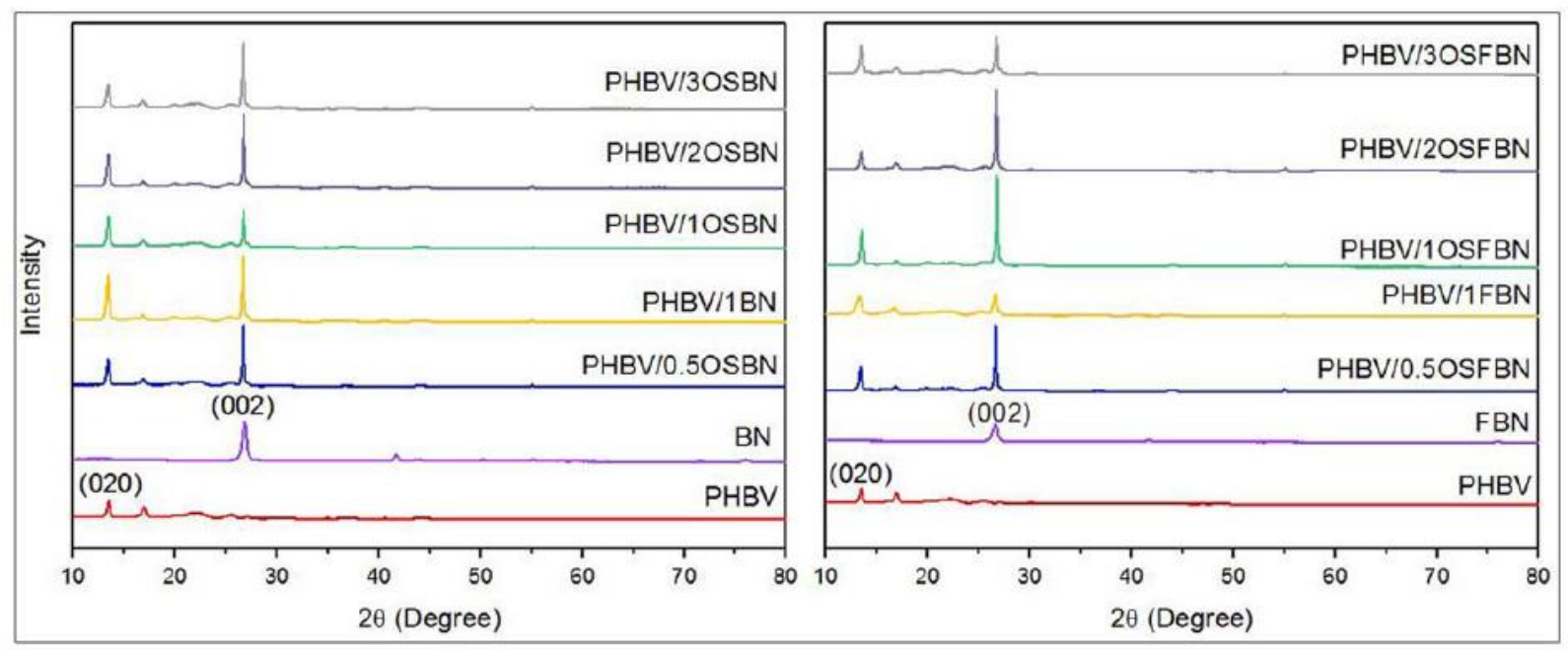

Figure 4 


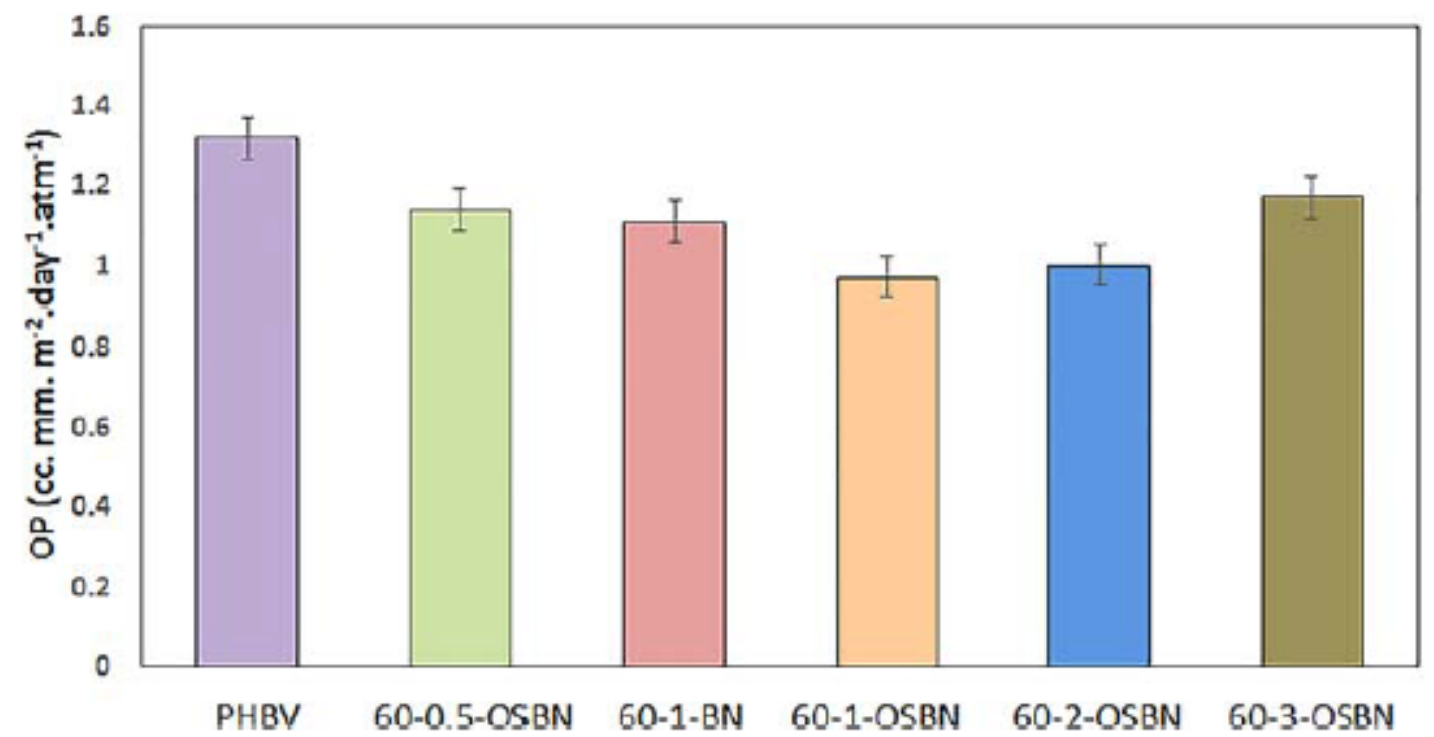

Figure 5

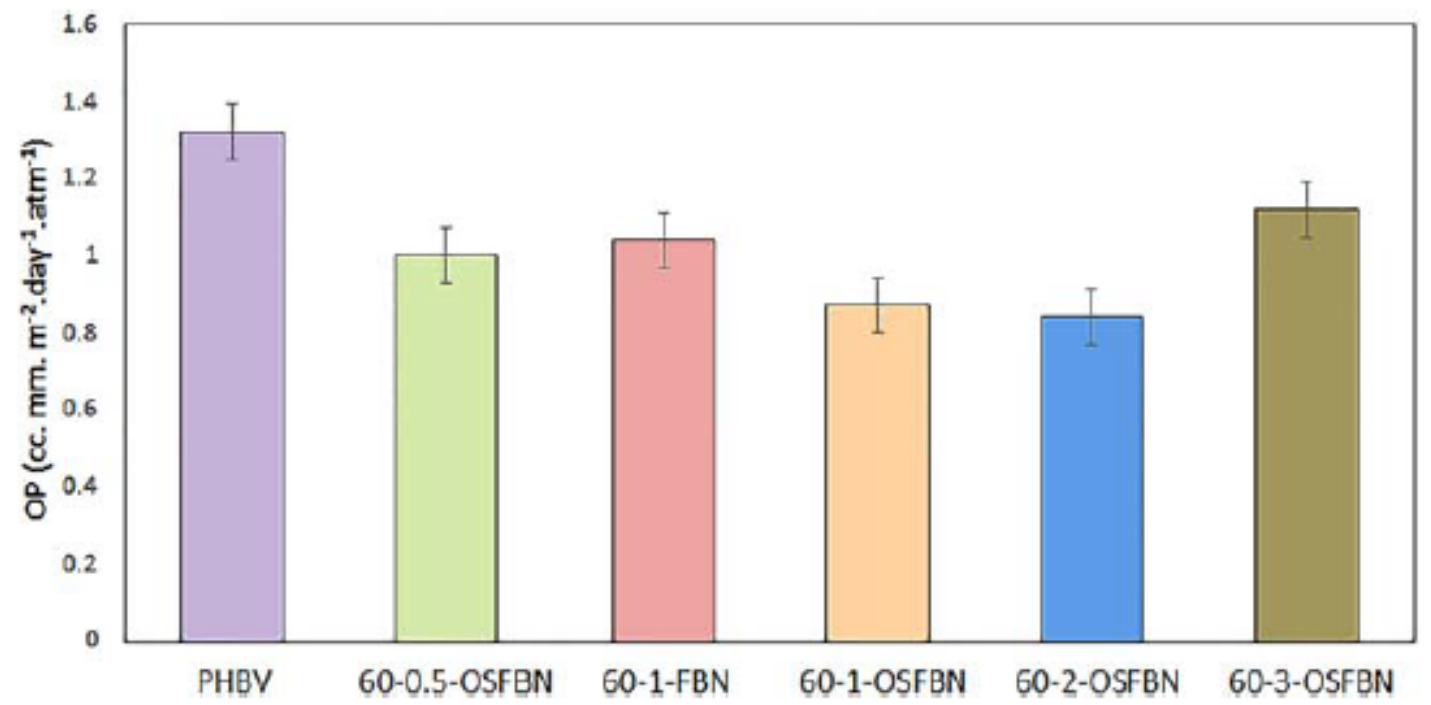

Figure 6 

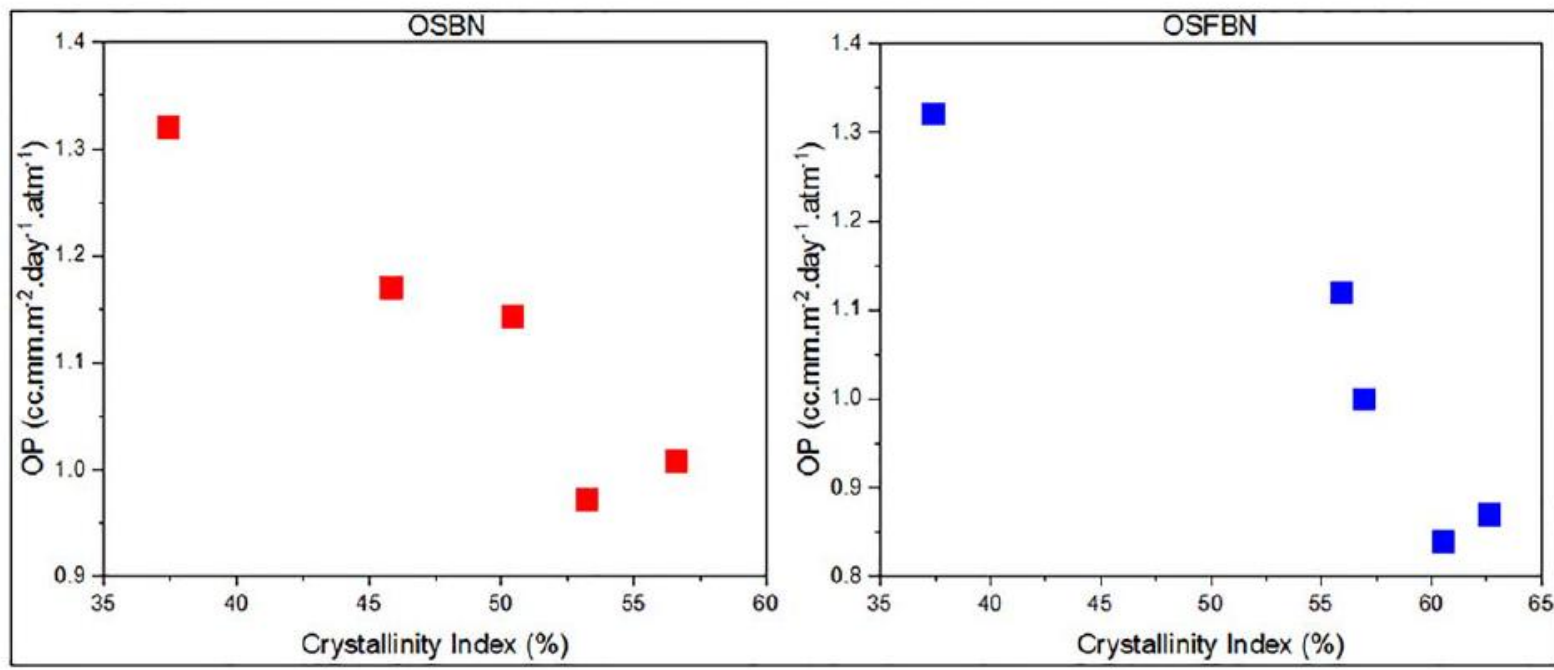

Figure 7

\section{CUSSLER (RANDOM ARRAY)}

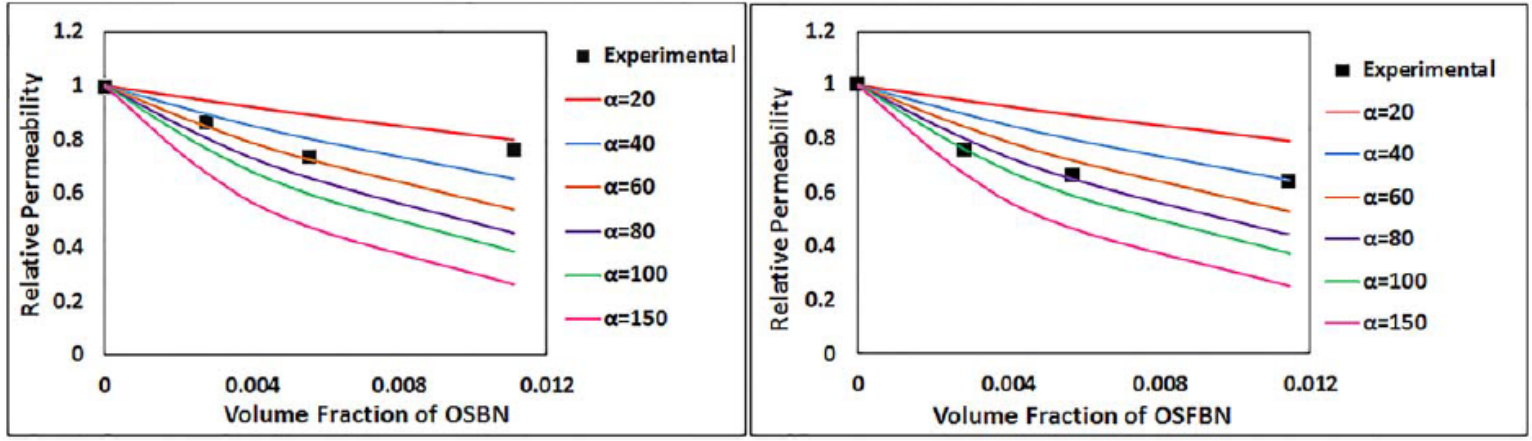

Figure 8

LAPE

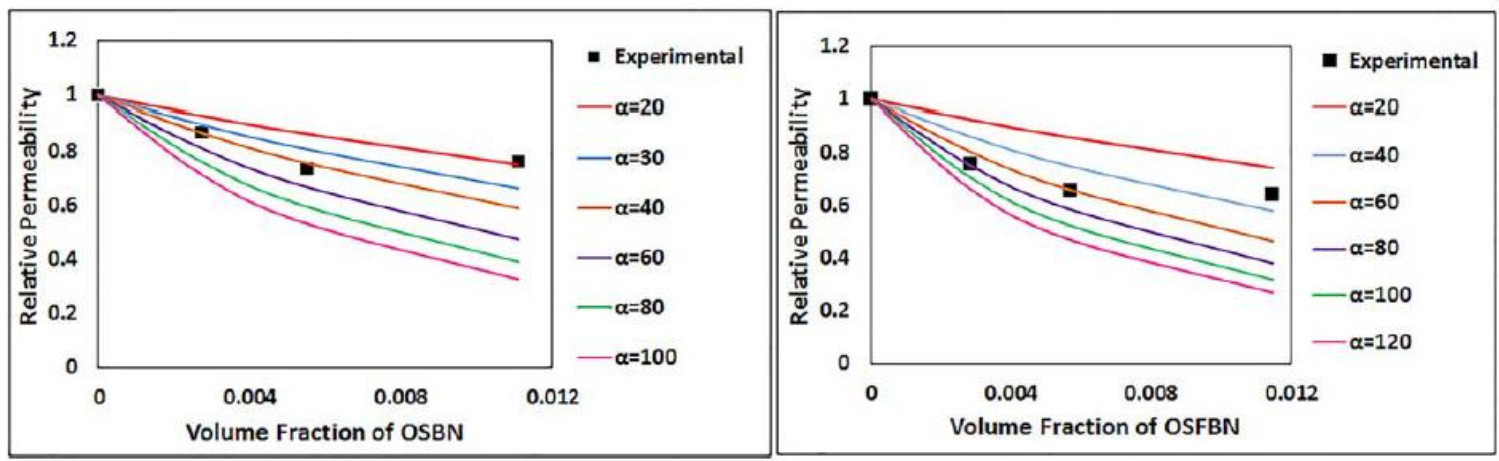

Figure 9 
TABLE 1. Codes of composites.

TABLE 2. FWHM, $d\left(A^{\circ}\right)$ and $D(n m)$ values for PHBV/BN nanocomposites

TABLE 3. FWHM, $d\left(A^{\circ}\right)$ and $D$ values for PHBV/FBN nanocomposites.

TABLE 4. Crystallinity index $(\mathrm{Cl})$ values of nanocomposites calculated from XRD.

TABLE 5. Phenomenological gas permeation models [47, 48]. [Color figure can be viewed at wileyonlinelibrary.com]

TABLE 6. Comparison between predicted and observed values of aspect ratio of OSBN and OSFBN for different models.

TABLE 7. Deviation (\%) in relative permeability $(\mathrm{Rp})$ of nanocomposites for barrier models. 
Table 1

Boron nitride

Sample code $\quad$ Boron nitride type content (wt $\%)$

PHBV

PHBV/0.5OSBN

BORTEK

0

$\mathrm{PHBV} / 1 \mathrm{BN}$

PHBV/1OSBN

$\mathrm{PHBV} / 2 \mathrm{OSBN}$

BORTEK 0.5

PHBV/3OSBN

PHBV/0.5OSFBN

PHBV/1FBN

PHBV/1OSFBN

PHBV/2OSFBN

1

PHBV/3OSFBN

$\begin{array}{ll}\text { SAINT-GOBAIN } & 0.5\end{array}$

PHPP325B

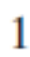

1

2

3

Table 2

\begin{tabular}{llllllll}
\hline & \multicolumn{3}{c}{$(020)$} & & \multicolumn{3}{c}{$(110)$} \\
\cline { 2 - 3 } \cline { 7 - 8 } $\begin{array}{l}\text { For BN } \\
\text { Samples }\end{array}$ & FWHM & $d(\AA)$ & $D(\mathrm{~nm})$ & & FWHM & $d(\AA)$ & $D(\mathrm{~nm})$ \\
\hline PHBV & 0.260 & 6.580 & 30.770 & & 0.380 & 5.240 & 21.140 \\
PHBV/0.5OSBN & 0.262 & 6.606 & 30.534 & & 0.416 & 5.285 & 19.307 \\
PHBV/1OSBN & 0.255 & 6.589 & 31.37 & & 0.439 & 5.258 & 18.30 \\
PHBV/2OSBN & 0.259 & 6.592 & 30.888 & & 0.421 & 5.260 & 19.077 \\
PHBV/3OSBN & 0.285 & 6.610 & 28.069 & 0.482 & 5.272 & 16.662 \\
\hline
\end{tabular}

Table 3 


\begin{tabular}{|c|c|c|c|c|c|c|}
\hline \multirow{2}{*}{$\begin{array}{l}\text { For FBN } \\
\text { Samples }\end{array}$} & \multicolumn{3}{|c|}{$(020)$} & \multicolumn{3}{|c|}{$(110)$} \\
\hline & FWHM & $d(\AA)$ & $D(\mathrm{~nm})$ & FWHM & $d(\AA)$ & $D(\mathrm{~nm})$ \\
\hline PHBV & 0.260 & 6.580 & 30.770 & 0.380 & 5.240 & 21.140 \\
\hline PHBV/0.5OSFBN & 0.245 & 6.614 & 32.652 & 0.440 & 5.263 & 18.253 \\
\hline PHBV/1OSFBN & 0.255 & 6.550 & 31.880 & 0.439 & 5.240 & 17.350 \\
\hline PHBV/2OSFBN & 0.250 & 6.550 & 32.000 & 0.426 & 5.240 & 18.860 \\
\hline PHBV/3OSFBN & 0.267 & 6.580 & 29.964 & 0.444 & 5.246 & 18.091 \\
\hline
\end{tabular}

Table 4

Sample

Crystallinity index from XRD (\%)

PHBV

$\mathrm{BN}$

PHBV/1BN

OSBN

PHBV/0.5OSBN

50.4

PHBV/1OSBN

53.2

PHBV/2OSBN

56.6

PHBV/3OSBN

45.8

FBN

PHBV/1FBN

42.6

OSFBN

PHBV/0.5OSFBN

56.9

PHBV/1OSFBN

62.6

PHBV/2OSFBN

60.5

PHBV/3OSFBN

55.9

Table 5 


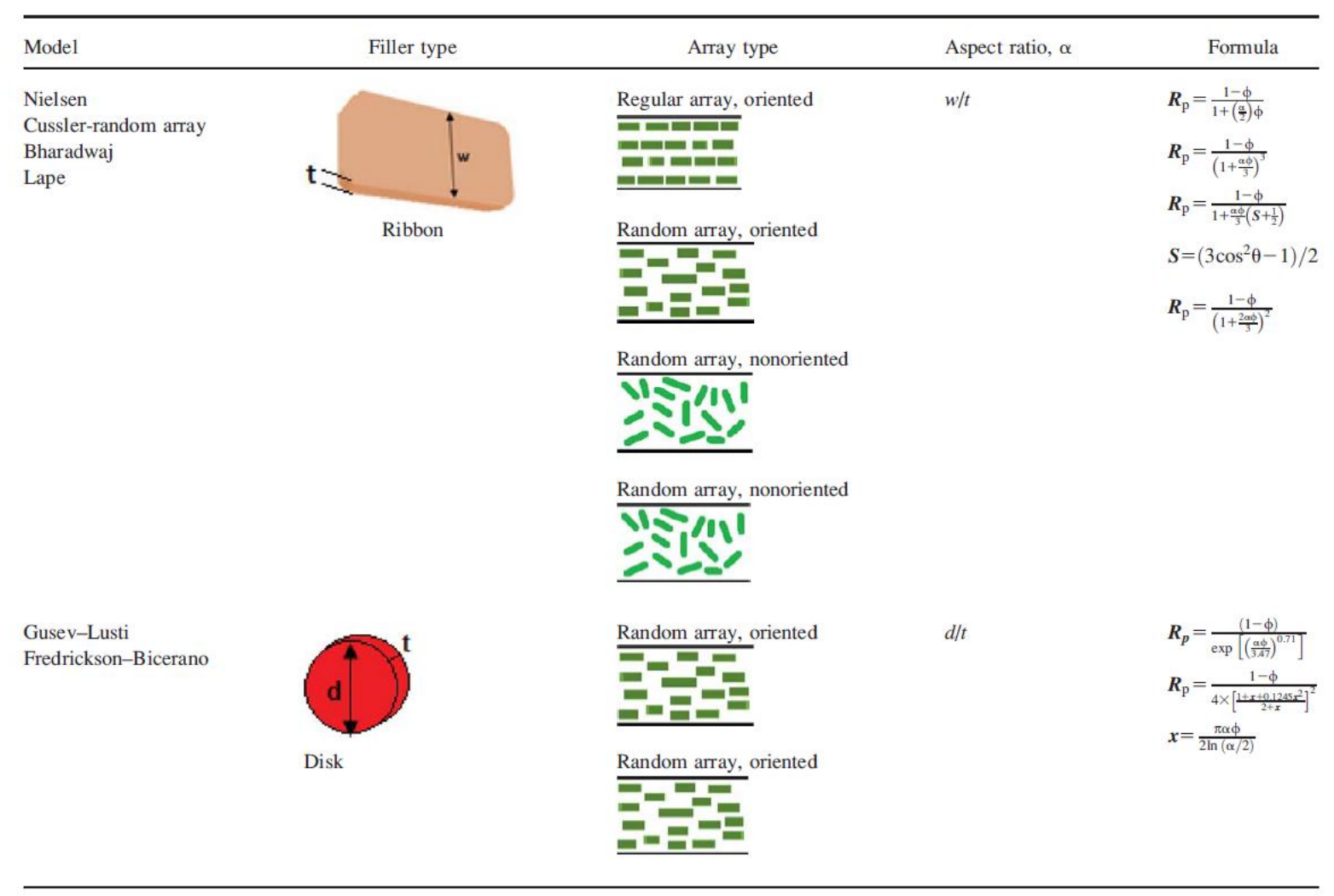

\section{Table 6}

Aspect ratio

BN type

$(\alpha)$ from SEM

Model

Aspect ratio $(\alpha)$

\begin{tabular}{llll}
\hline OSBN & 4.11 & $\begin{array}{l}\text { Cussler } \\
\text { (random array) }\end{array}$ & 40 \\
& & Lape & \\
OSFBN & 18.92 & Cussler & 60 \\
& & (random array) & 40 \\
& Lape & \\
\hline
\end{tabular}

Table 7 


\begin{tabular}{|c|c|c|c|}
\hline & $0.5 \%$ & $1 \%$ & $2 \%$ \\
\hline \multicolumn{4}{|c|}{ Cussler (random array) } \\
\hline$\overline{\mathrm{OSBN}}$ & 3.304 & 9.176 & 14.366 \\
\hline OSFBN & 11.582 & 9.188 & 16.815 \\
\hline \multicolumn{4}{|c|}{ Lape } \\
\hline OSBN & 3.402 & 9.572 & 13.235 \\
\hline OSFBN & 13.811 & 13.748 & 9.364 \\
\hline
\end{tabular}

